\title{
ARTIGOS
}

\section{COMO LER MARX NO CARRO-FORTE: DILEMAS DO ENSINO SUPERIOR BRASILEIRO}

\author{
ALEXANDRE BARBOSA PEREIRA'
}

\section{RESUMO}

A proposta desse artigo é, a partir do relato de minha experiência como professor em uma instituição privada de ensino superior lucrativo na cidade de São Paulo, apresentar um panorama de quem são os estudantes que têm ingressado em instituições desse tipo. O texto traz uma reflexão sobre a condição social e econômica desses estudantes, que formam um público universitário bastante diversificado e singular. A minha inserção numa faculdade privada proporcionou também uma reflexão sobre as condições de trabalho docente. Além disso, indaga-se sobre que espaço haveria para o ensino de Ciências Sociais para estudantes de outras formações num contexto de ampliação do acesso, mas sem democratização do saber.

ENSINO SUPERIOR • ESCOLA PARTICULAR • TRABALHO DOCENTE • ESTUDANTES

\section{HOW TO READ MARX IN AN ARMORED TRUCK: DILEMMAS OF BRAZILIAN HIGHER EDUCATION}

\section{ABSTRACT}

Drawing on the report of my experience as a professor in a profitable private higher education institution in São Paulo city, Brazil, this article presents an overview of who the students of this type of institutions are. It reflects not only on the social and economic conditions of these students, who constitute a quite diversified and unique university audience, but also on the working conditions of professors. In addition, it inquires whether there is room for teaching social 
COMMENT LIRE MARX DANS UN FOURGON BLINDÉ: DILEMMES DE L'ENSEIGNEMENT SUPÉRIEUR BRÉSILIEN

RÉSUMÉ

L'objectif de cet article est de présenter, à partir de mon expérience d'enseignant dans un établissement d'enseignement supérieur privé à but lucratif de la ville de São Paulo, un aperçu des étudiants qui accèdent à ce type d'établissements. Le texte apporte une réflexion sur la condition sociale et économique de ces étudiants, qui forment un public universitaire diversifié et singulier. Mon insertion dans une faculté privée est aussi source de réflexion sur les conditions de travail de l'enseignant. Par ailleurs, cet article cherche à savoir quelle est la place de l'enseignement des sciences sociales pour les étudiants suivant d'autres formations, dans un contexte d'élargissement de l'accès aux études supérieures, sans vraie démocratisation du savoir.

ENSEIGNEMENT SUPÉRIEUR • ÉCOLE PRIVÉE • TRAVAIL D'ENSEIGNEMENT • ÉTUDIANTS

\section{CÓMO LEER MARX EN EL CAMIÓN TRANSPORTADOR DE CAUDALES: DILEMAS DE LA EDUCACIÓN SUPERIOR BRASILEÑA}

RESUMEN

La propuesta de este artículo es, a partir del relato de mi experiencia como profesor en una institución privada de enseñanza superior rentable en la ciudad de São Paulo, presentar un panorama de quienes son los estudiantes que ingresan en instituciones de este tipo. El texto trae una reflexión sobre la condición social y económica de estos estudiantes, que forman un público universitario bastante diversificado y singular. Mi inserción en una facultad privada también me proporcionó una reflexión sobre las condiciones del trabajo docente. Además, se indaga sobre el espacio que habría para enseñar Ciencias Sociales a estudiantes de otras formaciones en un contexto de ampliación del acceso, pero sin democratización del saber.

EDUCACIÓN SUPERIOR • ESCUELA PRIVADA • TRABAJO DOCENTE • 
AVIA PEDIDO À TURMA, NAQUELA SEMANA, A LEITURA DA PRIMEIRA PARTE dO Manifesto comunista. Assim, eu poderia apresentar, de forma bem introdutória, e a partir de um texto mais acessível, um panorama sobre o sistema capitalista e o processo de globalização pela perspectiva relevante e sempre atual de Karl Marx. Tratava-se de uma disciplina, chamada Sociologia e Antropologia, para estudantes do período noturno do curso de Direito de uma faculdade privada, de pequeno porte, da Zona Leste de São Paulo. Ao final dessa aula específica, um dos alunos, Alex, dirigiu-se a mim para reclamar do quanto estava complicado conciliar a faculdade com o trabalho e que, por isso, estava com dificuldade para ler os textos. Contou-me que saía às 5 horas da manhã de sua casa, no bairro da Penha, na Zona Leste, para a Barra Funda, na Zona Oeste, a fim de iniciar a jornada de trabalho numa empresa de transporte de valores. Depois, à noite, cursava a faculdade no horário das 19 às 23 horas. Alex trabalhava como agente de segurança privada. Começou a estudar Direito com o intuito de progredir profissionalmente e ampliar seu repertório para ter maiores condições de passar em alguma prova de concurso - seu maior sonho era o serviço público, por causa da estabilidade. Ele era casado e tinha um filho. Nesse dia, entretanto, disse-me que a leitura de Marx havia lhe causado certo mal-estar ou ao menos lhe feito pensar mais sobre o seu trabalho e sua rotina diária. Não, ele não passou a questionar o sistema capitalista, nem elaborou uma reflexão a respeito do conceito marxista de alienação. Na verdade, 
ele começou a se preocupar mais com a dificuldade em cursar uma faculdade e realizar todas as tarefas que ela demandava e ainda ter um trabalho desgastante que tomava grande parte de seu tempo.

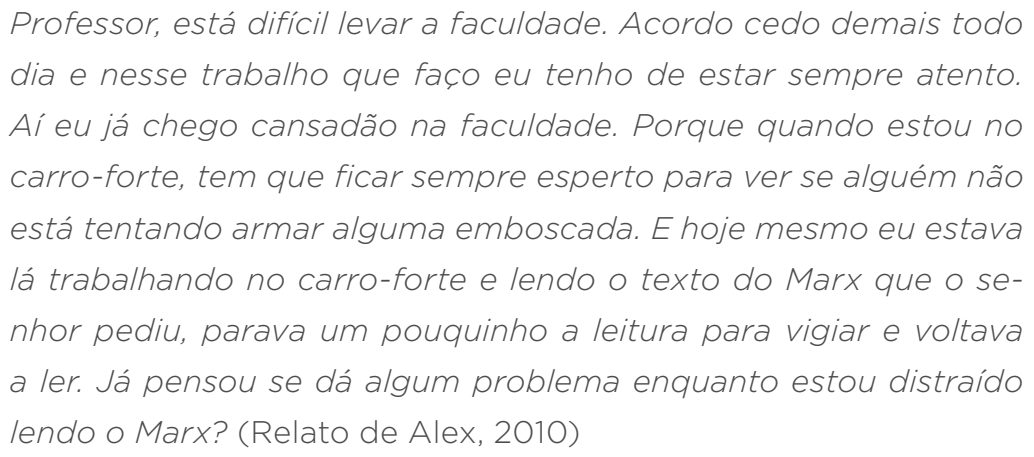

Essa foi apenas uma das muitas situações que vivenciei quando atuei, entre 2010 e 2011, como docente do curso noturno de Direito dessa faculdade. Ao regressar para casa, após esse dia de aula, registrei tal relato, pois percebi o quanto era reveladora essa observação de Alex. Interessou-me descrever justamente a riqueza dessa experiência, que se manifestava na angústia do estudante, bem como em todos os desafios profissionais e de compreensão da realidade social brasileira contemporânea que se apresentaram a partir dessa minha atuação como professor. Destaco, assim, alguns eventos e as histórias de vida de alguns alunos $^{1}$ que conheci. O texto divide-se em duas partes. Na primeira, abordo minha experiência docente com um público formado majoritariamente por estudantes das classes populares, que trabalhavam e eram os primeiros da família a ingressarem num curso superior. Descrevo as questões que me surgiram e também as estratégias, nem sempre bem-sucedidas, que tentei desenvolver para que pudesse, minimamente, discutir alguns temas que considerava fundamentais para quem não seria, nem tinha a pretensão de ser, cientista social. Em seguida, na segunda parte, apresento um levantamento que fiz com os estudantes, tentando delinear um perfil mais aprofundado sobre eles, apontando para uma discussão mais geral sobre as classes populares no Brasil contemporâneo e seu acesso ao ensino superior. O percurso encerra-se com uma reflexão sobre o ensino de Ciências Sociais para alunos de outros cursos e, particularmente, sobre as condições de trabalho nas instituições privadas de ensino.

Trata-se, portanto, da descrição de uma experiência localizada. Contudo, entendo que mesmo um recorte diminuto da realidade pode fornecer pistas que ajudam a pensar sobre questões mais abrangentes. A partir de uma perspectiva qualitativa, tento demonstrar os significados dessa experiência de inserção no ensino superior privado, do ponto de vista tanto de minha atuação como docente quanto dos estudantes com 
quem interagi por um ano. Apesar da formação em Antropologia Social e mesmo de ter realizado uma pesquisa etnográfica em escolas de bairros da periferia de São Paulo, devo logo explicitar que este trabalho não é o resultado de uma pesquisa etnográfica clássica, de longo prazo, embora bastante influenciado por essa perspectiva. Como aponta Wright Mills (2009), a produção do conhecimento nas Ciências Sociais é, ao mesmo tempo, o resultado da escolha de uma carreira e de um modo de vida. Trata-se, assim, de um ofício, de uma produção artesanal em que a nossa própria experiência de vida é usada como base para o trabalho intelectual. O que apresento aqui é justamente essa junção entre a vida e a reflexão acadêmica, a fim de, por intermédio dessa experiência particular, discutir questões mais amplas sobre temas como educação, ensino de Ciências Sociais, políticas educacionais, ensino superior, classes sociais, etc.

$\mathrm{O}$ artigo parte de uma pesquisa de inspiração antropológica, na medida em que seu objetivo principal é, conforme expõe Clifford Geertz (1989, p. 19-20), "tirar grandes conclusões a partir de fatos pequenos, mas densamente entrelaçados". Por isso, a descrição densa de minha experiência docente e interativa com os estudantes não retira a força e a importância desse empreendimento particular de pesquisa, ainda mais considerando que, como afirmam Maurice Tardif e Claude Lessard (2014), o trabalho de professor é justamente marcado pela interação social. Trata-se, portanto, de um tipo especial de trabalho, pois tem seres humanos como objeto de sua ação e constitui-se fundamentalmente como um empreendimento interativo. Isso faz com que a docência tenha como objeto "as relações humanas com pessoas capazes de iniciativa e dotadas de uma certa capacidade de resistir ou de participar da ação dos professores" (TARDIF; LESSARD, 2014, p. 35). Ou seja, nesse contexto, a questão do respeito ou do reconhecimento de uma autoridade legítima no professor mostra-se fundamental. Raewyn Connell (2010) reafirma essa perspectiva interacional do trabalho docente e prossegue ressaltando como o aspecto emocional é capaz de interferir nesse trabalho interativo. Cabe, assim, ao professor, lidar com esse conjunto de emoções - simpatias, antipatias, medo, satisfação, tédio, etc. - que fluem dos alunos para ele e dele para os alunos. As minhas interações e esse fluxo de emoções que envolveram minha inserção numa instituição privada de ensino superior constituem o que será apresentado em busca de produzir uma reflexão sobre questões como o trabalho docente, o ensino de Ciências Sociais, o ensino superior e as classes populares no Brasil. Assim, uma pesquisa que parte não apenas da observação, mas também da participação efetiva no contexto estudado, pode contribuir, principalmente quando se trata de instituições educacionais, para o que os autores Hugh Mehan (1979) e Alain Coulon (2008) chamam de 
abrir a caixa-preta dos diversificados mecanismos que possibilitam o êxito ou o fracasso de estudantes e professores.

\section{AULA NO ESCURO: DESCRIÇÃO DA EXPERIÊNCIA DOCENTE NO ENSINO SUPERIOR PRIVADO}

A experiência como docente dessa faculdade particular foi marcante para mim. Desde os primeiros momentos já vislumbrei que aquele seria um período de dificuldades, mas também de descobertas, sobre o qual valeria refletir de forma mais aprofundada posteriormente. Após sair desse trabalho, durante muito tempo ainda amadureci a ideia de não apenas descrevê-lo, mas também de discutir as questões que ele me suscitou. Isso porque, já em minha primeira aula, tive de enfrentar uma série de desafios. Georges Gusdorf (2003) descreve, aliás, como o confronto da primeira aula é o momento crucial para alunos e professores, pois decidirá o futuro daquela turma e mesmo de como será empenhado seu tempo no próximo ano ou semestre. Nesse primeiro momento é que começam inclusive a surgir certas classificações dos professores, como a do professor que não sabe se impor ou a do que consegue obter o respeito do público. Cada nova primeira aula para uma nova turma ou para um novo ano ou semestre que se inicia é também um grande teste para os professores. Esse é o momento em que os olhares, em meio ao barulho ou ao silêncio, cruzam-se.

\footnotetext{
O professor observa a classe, a classe observa o professor. De um lado e de outro, examina-se, espia-se, desafia-se, cruzam-se lanças. Para as duas partes, a prova é perigosa, e é bem compreensivel que alguns professores não a suportem, vencidos desde esse momento pela coletividade perante a qual se sentem reduzidos a uma irremediável minoria. [...] É preciso afirmar sua presença e fazê-la prevalecer sobre um grupo de jovens naturalmente turbulentos, cuja boa vontade não se adquire de antemão. Nem todas as pessoas têm temperamento de domador. (GUSDORF, 2003, p. 37)
}

Retomando um trabalho de Howard Becker, Blanchee Geer, Everett Hughes e Anselm Strauss (1977) sobre o cotidiano de estudantes do curso de medicina de uma universidade dos Estados Unidos, Alain Coulon $(2008$, p. 39) afirma que também para os estudantes os primeiros momentos na universidade e, particularmente, o primeiro ano é o mais importante para aprender as regras da instituição: "É durante esse ano que se aprende a viver esse novo papel".

Na minha primeira aula, o confronto foi um pouco mais tenso do que comumente seria, pois os alunos da turma, em que ficaria res- 
ponsável por lecionar Sociologia e Antropologia às terças-feiras e Teoria Política às quintas-feiras, estavam indignados pela indefinição dos docentes que lhes dariam aula. Outros dois docentes já tinham ministrado aulas provisoriamente, transcorrido quase um mês do semestre letivo. Alguns alunos, inclusive, já tinham criado certa afinidade com os docentes. Por isso, quando cheguei houve resistências. As falas de indignação eram generalizadas. O estudante Gilmar, que sentava logo nas primeiras carteiras, avisou-me: "Essa classe está um braseiro, professor".

Eu, então, ainda um pouco inseguro, embora me considerando bem preparado para aquela primeira aula em que introduziria o percurso das disciplinas, comecei a me apresentar. Outro aluno, o Jonathan, então com 36 anos, interrompeu-me para perguntar sobre minha formação. Fez questão de dizer-me, com certo ar pedante, que era engenheiro químico com mestrado pela Universidade Federal do Rio Grande do Norte e que iniciara um doutorado em engenharia na Universidade Estadual de Campinas. Ele falou ainda que gostara muito do docente anterior e que queria ter continuado com ele. Estranhei que um engenheiro formado, mestre e já a realizar um doutorado estivesse cursando Direito, uma área totalmente diferente de sua formação original, numa faculdade particular de pequeno porte e nenhum prestígio. Contudo, retomarei adiante como descobri o motivo da presença desse estudante com perfil tão destoante dos outros naquele estabelecimento. Não bastassem os questionamentos à minha presença e à indefinição dos docentes que assumiriam as disciplinas do curso naquele primeiro semestre, as dificuldades na primeira aula tornaram-se ainda maiores, pois, devido a algum problema no sistema elétrico do prédio da faculdade, ficamos no escuro. Aguardei um tempo para ver se era momentâneo e, como perdurou e os estudantes reclamavam que queriam aula, saquei uma pequena lanterna que, por acaso, estava em minha mochila e terminei de apresentar as disciplinas no escuro mesmo, iluminando meu rosto para poder ser visto pelos alunos. Fiquei conhecido, desde então, como o professor que deu aula no escuro. Nada mais condizente com a forma como iniciei meu trabalho nessa faculdade e com a própria perspectiva para a carreira docente em instituições como essa. Contudo, a ousadia fez-me angariar a atenção inicial dos alunos e algum respeito, ainda que momentâneo.

Apesar de toda a precariedade das condições de trabalho e de todos os problemas com os quais se tem de lidar cotidianamente, conseguir uma vaga de docente no ensino superior privado não é tarefa das mais fáceis. No meu caso, a instituição precisou contratar com urgência, pois as aulas já tinham começado havia quase um mês. No processo de seleção, em conversa com a coordenadora do curso de Direito, para o qual trabalharia, efetivamente constatei que a inserção profissional em estabelecimentos de "ensino superior privado lucrativo" era bastante 
disputada e se dava fundamentalmente pela indicação. Ainda durante a entrevista, outro docente, mais velho e que já trabalhava há um bom tempo por lá, interrompeu a conversa para perguntar se a vaga para a qual eu concorria era "aquela de Ciências Sociais para o curso de Direito", pois tinha alguém para indicar. Ela respondeu que estava quase terminando a seleção e que, provavelmente, já teria fechado a pessoa que ocuparia a vaga.

As condições de trabalho, confesso, não eram das mais animadoras, e o salário era baixo, pouco mais de $\mathrm{R} \$ 20,00$ por hora de aula. Eu preencheria, assim, no primeiro semestre em que atuei nesse local, duas noites de aula, das 19 às 23 horas, ou oito horas de aula por semana, o que, no fim de 2010, dava cerca de R\$ 900,00 por mês. Além do baixo salário, a definição das aulas pelas quais cada docente ficaria responsável sempre atrasava. Assim, somente era possível saber de uma redução ou aumento das horas de aula e das disciplinas pelas quais se ficaria responsável a poucos dias do início do semestre letivo. Essas foram as minhas condições de ingresso como docente no chamado ensino superior lucrativo. Wilson Almeida (2014a) serve-se dessa categoria, ensino superior lucrativo, como forma de diferenciar essa modalidade de educação privada que visa fundamentalmente ao lucro, quase sempre em detrimento da qualidade do ensino e de boas condições de trabalho docente, das instituições confessionais, como as universidades católicas, mais tradicionais e com maior preocupação com a qualidade. Apesar desse panorama conturbado, a possibilidade de atuar no ensino superior e mesmo de adquirir certa experiência na docência motivara-me a aceitar essas condições. Posteriormente, essa atividade profissional de um ano foi-me útil para ocupar uma vaga de professor substituto numa universidade federal, cujo edital de seleção exigia um ano de docência no ensino superior. A desorganização dessa instituição privada, entretanto, propiciava, por outro lado, que eu definisse de modo totalmente autônomo e independente o programa das aulas. Aconteceu, nesse caso, o contrário do que eu ouvia de colegas que já haviam trabalhado em estabelecimentos privados lucrativos de maior porte, cujas leituras, aulas e provas já eram definidas previamente, com planos de ensino padronizados e mesmo com provas que chegavam em embalagens fechadas para o docente, sem que houvesse qualquer participação deste em sua elaboração.

Nunca esperei que fosse fácil essa experiência docente, tanto pelos relatos de colegas que já lecionavam em outros estabelecimentos privados, quanto pela minha própria experiência de pesquisa em escolas públicas de bairros da periferia de São Paulo. Nesta, compreendi e aprendi que o trabalho docente envolve um equilíbrio bastante complicado e nunca plenamente encontrado do estabelecimento de relações mais afetuosas e próximas aos estudantes com a constituição de limites 
e afastamentos, que demonstrem claramente o que é permitido e o que não é em aula. Fundamental, portanto, a articulação de certa autoridade legítima que garanta aos estudantes reconhecerem no docente alguém autorizado a conduzir uma discussão ou a orientá-los em seus estudos. Do contrário, há grande chance de um aluno atender o telefone celular em sala de aula ou de outro conversar em voz alta, atrapalhando a condução do trabalho docente.

Contudo, ainda que preparado para tal atividade, devo confessar que não tenho uma personalidade autoritária e possuo certa dificuldade de imposição de regras mais rígidas. Gosto de conduzir as aulas de modo mais tranquilo e com maior espaço para os estudantes participarem. Entretanto, mesmo numa faculdade, foi preciso agir com firmeza em muitos momentos nos quais a atenção à aula dissipava-se de modo a atrapalhar o seu andamento, com conversas paralelas em voz alta ou mesmo com brincadeiras. Tive de, ao mesmo tempo, cobrá-los por uma postura mais atenta às discussões e mais participativa em sala de aula, além de tentar estabelecer estratégias que lhes chamassem mais a atenção. Uma delas consistiu em utilizar mais dos recursos de apresentações visuais pelo Power Point. Curiosamente, os estudantes paravam mais para prestar atenção nos slides projetados do que em mim falando sozinho à frente da sala. Se houvesse imagens então, ainda melhor. As regras e as bases da configuração das relações com os estudantes, porém, tinham de ser repostas, reforçadas e reconstituídas constantemente, a partir de suas ações.

Em cenário tão peculiar como esse, definir o que e como ensinar é um dos maiores desafios. Na preparação dos planos de ensino para a disciplina Teoria Política, resolvi trabalhar com excertos de autores clássicos e suscitar algumas discussões que pudessem ser interessantes para estudantes do curso de Direito, como, por exemplo, sobre o sistema partidário e eleitoral no Brasil. Essa foi uma estratégia que, embora houvesse deixado transparecer problemas de entendimento e de formação no ensino básico dos estudantes, mostrou-se, nesse caso, bastante profícua, pois alguns autores clássicos pareceram-lhes bastante atrativos. Durante as discussões dos excertos de textos clássicos da política, Thomas Hobbes foi um dos autores que chamou bastante a atenção dos alunos, fazendo com que participassem mais das discussões em sala de aula. Muitos adoraram o Leviatã e interpretaram Hobbes a partir da Bíblia, leitura com a qual tinham maior afinidade, porque a estudavam ou pelo menos estabeleciam um maior contato com ela nas igrejas evangélicas que uma boa parte deles frequentava. Mesmo estudantes que costumavam ser apáticos mostraram-se mais atentos à aula nesse dia. Muitas vezes concordaram com alguns pressupostos de Hobbes. Outro autor que chamou a atenção e que alguns já tinham ouvido falar era Maquiavel. A maioria queria aprender como ser um gover- 
nante "maquiavélico" ou detectar, entre os então governantes, traços de maquiavelismo.

A questão da religiosidade despontou, aliás, como uma dimensão extremamente relevante no contexto das aulas, aparecendo em diferentes momentos. Um dos estudantes, o Gilmar, que inclusive apresentou-se como pastor evangélico, mostrava-se muito interessado por discussões políticas e sempre relacionava questões das aulas com assuntos religiosos. Numa aula de antropologia em que conduzi uma discussão sobre papéis de gênero, a partir da exibição de um curta-metragem intitulado Acorda Raimundo... Acorda!, ${ }^{2}$ Gilmar teve uma participação bastante peculiar. O filme retrata a vida de um casal cuja relação inverte as expectativas do senso comum, pois nele é a mulher quem acorda para trabalhar fora, enquanto o marido fica responsável pelos afazeres domésticos e cuidado dos filhos. Além disso, apresenta uma cena de violência doméstica em que a mulher, que desempenha o papel social de dominação exercido hegemonicamente pelos homens, retorna do trabalho alcoolizada e agride o marido. Nesse momento final, Raimundo acorda assustado e percebe que havia, na verdade, sonhado, manda a esposa ir preparar logo o café dele, pois precisava trabalhar e exclama: "Ainda bem que foi só um sonho!". O objetivo do filme, com essa inversão, é justamente desnaturalizar as representações de gênero, explicitando a dominação masculina. Na discussão sobre o filme, Gilmar disse ter chegado a uma conclusão, a de que Deus havia feito as coisas muito certinhas, o homem e a mulher com seus papéis muito bem definidos e que, portanto, não se deveria mexer nisso, nem inverter as designações divinas. Embora algumas estudantes tenham discordado dessa afirmação e criticado o machismo nela contido, tal percepção mais conservadora do mundo e das relações sociais era bastante comum entre a maioria deles.

Minha ingenuidade de principiante na profissão pôde ser testada em mais de um momento à frente da turma. Como quando pedi aos alunos que realizassem, como avaliação, um trabalho escrito que poderia ser a resenha de uma das leituras ou um texto que comentasse um tema a partir de três autores estudados. Meu objetivo com essa atividade era até mesmo diagnosticar problemas de leitura e escrita, tendo em vista que muitos já tinham manifestado dificuldades de compreensão, e orientá-los em como tentar superar as dificuldades. Ao receber os trabalhos, entretanto, percebi que a maioria era plágio de textos encontrados na internet. Disse-lhes que havia duas possibilidades para aquilo ter ocorrido: má-fé ou falta de experiência com a realidade do mundo acadêmico. Explicitei, no entanto, que, de todo modo, era uma atitude condenável. Contudo, afirmei que preferia acreditar que tinham feito aquilo devido à inexperiência, por isso daria zero aos trabalhos plagia- 2 dos, mas ainda aceitaria que entregassem uma versão nova e original 
do trabalho; poucos o fizeram no final. Nesse momento, Jonathan, o estudante que se apresentou como engenheiro químico e costumava dizer que aquela faculdade era muito ruim e humilhar os colegas dizendo que eles eram burros e não tinham uma boa formação, deixou revelar o mistério de sua inusitada presença ali. Ele havia feito um trabalho de 20 páginas que era para ser de, no máximo, duas. Ao entregar-me disse que não conseguia escrever em poucas páginas e que pediu até ajuda de outra professora da faculdade para fazê-lo. Desconfiei da pretensa genialidade desse estudante e bastou a busca de algumas frases de seu trabalho no Google para descobrir que se tratava na verdade de uma grande colcha de retalhos, formada por trechos plagiados de diferentes trabalhos. Ele, na verdade, utilizou-se de um método mais sofisticado do que o dos colegas, em vez de plagiar de apenas um local, diversificou as fontes, copiando integralmente as várias partes que compuseram o trabalho final.

Quando li as notas e Jonathan estava entre aqueles que tiraram zero e que, portanto, haviam plagiado, os outros estudantes, que nutriam muito pouca simpatia para com o mesmo, entreolharam-se e começaram a questionar aquele que se declarava superior e os humilhava. Alguns buscaram o nome completo dele no Google e descobriram uma série de denúncias de plágio, inclusive de artigos científicos inteiros. Jonathan, percebendo ter sido pego novamente, ficou indignado e quis conversar pessoalmente comigo. Disse que eu não poderia fazer aquilo com ele, que era maçom, que a irmã era juíza, que o pai era militar e que reclamaria de minha postura na coordenação da faculdade e que exigia o trabalho de volta. Eu apenas disse que ele havia plagiado e que não devolveria o trabalho e que ele poderia reclamar com quem quisesse, não voltaria atrás de minha decisão. Posteriormente, em sala de aula, numa atividade em que os estudantes discutiam, em grupo, questões sobre o texto lido para aquele dia, Jonathan resolveu provocar-me falando alto e dizendo que eu era um péssimo professor. Ao chamar-lhe a atenção, apontando que ele estaria atrapalhando o trabalho dos colegas, gritou e xingou alguns palavrões. Eu, calmamente, pedi que se retirasse da sala, pois estava desrespeitando e incomodando os colegas que tentavam estudar. Ele saiu dizendo que iria à coordenação para reclamar de mim - expediente comum entre alunos, reclamar com a coordenação sobre qualquer questão que não os deixasse satisfeitos. Quando ele se retirou da sala, a turma inteira aplaudiu-me.

Nesse mesmo dia, após esse incidente com Jonathan, um dos alunos veio até mim e pediu para que eu buscasse no Google o nome do referido aluno junto com a palavra plágio. Muitos deles já estavam bastante irritados com a postura de Jonathan, pois ele constantemente interrompia a aula com o objetivo de mostrar que detinha mais conhecimento do que os colegas. Dois alunos, um que trabalhava como carce- 
reiro e outro como motorista, chegaram até a intimidá-lo para que ele não atrapalhasse mais as aulas, como me revelaram posteriormente. Os estudantes haviam, na verdade, descoberto, ao pesquisar na internet, que Jonathan tinha sido desligado de um doutorado numa universidade federal por uma série de acusações de plágio em artigos científicos e mesmo no próprio projeto de pesquisa. O caso foi noticiado, na época, por alguns jornais de grande circulação no Brasil. Mais do que um caso exótico ou uma anedota, essa situação que enfrentei aponta para dois elementos fundamentais da realidade do ensino superior privado nos últimos anos. O primeiro diz respeito à sua composição bastante diversificada, uma vez que, apesar de uma prevalência de indivíduos com menor poder aquisitivo, não se pode tomá-los como uma massa homogênea ou indiferenciada, pois, mesmo entre os que poderiam ser incluídos no que denomino aqui como classes populares, havia uma série de nuances, como renda, origem social e formação escolar. Já o segundo aponta para os desafios da atuação profissional num contexto de agravamento da crise da autoridade docente e no qual certa imagem do professor universitário, concebida, inicialmente, como posição social que deteria certo respeito e admiração, perde força. Essa questão, aliás, tornava-se ainda mais complicada considerando que se tratava de uma coletividade composta por uma grande quantidade de indivíduos cuja experiência de cursar uma faculdade era pioneira em suas famílias. Além disso, eles encaravam seu ingresso num curso superior como a aquisição de um serviço contratado para lhes proporcionar ascensão econômica e aumento de reconhecimento social.

Na formação acadêmica de cursos voltados ou com alguma interface com a educação, pouco se discute sobre o ensino de Ciências Sociais para outros cursos e menos ainda sobre o seu ensino numa instituição privada lucrativa voltada para as classes populares. Mesmo as licenciaturas para o ensino de Sociologia no ensino médio - que deveriam contribuir para o enfrentamento do desafio de ensinar Ciências Sociais para quem não escolheu diretamente estudar essa temática e tem pouca abertura para um conhecimento que não tem aplicações práticas diretas para o chamado mercado - não costumam fazer. Como afirma Coulon (2008), ao analisar a realidade francesa, os professores de ensino superior, curiosamente, seguem como profissionais que não recebem uma formação efetiva para um dos principais aspectos de seu trabalho, o de transmitir conhecimentos. Ao discutir o ensino de Sociologia para os que não seguirão sua carreira nessa área, Irlys Barreira (2014) afirma que, com o pragmatismo orientando as escolhas profissionais, os professores de Sociologia e das Ciências Sociais de uma maneira geral veem-se, constantemente, confrontados, pelos estudantes de outras áreas e mesmo do ensino médio, pela indagação: "Afinal, para que serve aprender isso?” O relato que trago aqui é, certamente, um caso 
dos mais extremos e complicados para se pensar uma disciplina acadêmica voltada para estudantes que, na maioria dos casos, afirmam não ver nela qualquer utilidade para o que entendem como a sua atuação profissional. Contudo, esse contexto suscitou muitas reflexões a esse respeito. Uma delas remete à discussão feita por Bernard Lahire (2014, p. 45), que defende que a questão sobre a utilidade do ensino de Sociologia deve sempre remeter a outra: “Para que serve a Sociologia?” Para o autor, a Sociologia deveria estar no currículo de todos os estudantes desde os primeiros anos de escolarização como uma maneira de dar "uma resposta adequada (e muito melhor que outras) às exigências modernas de formação escolar dos cidadãos" (LAHIRE, 2014, p. 50). Arrisco-me a ir um pouco além e afirmar que, no contexto atual brasileiro, o ensino de Sociologia, no ensino médio ou superior, deve ser capaz de proporcionar elementos para a realização de leituras do mundo. Ou seja, o estudante deve ser capaz de, a partir do repertório das Ciências Sociais, construir suas próprias leituras do cenário econômico e político, por exemplo, ou, em alguns casos mais complicados de formação básica, até mesmo tentar entender um texto mais complexo.

Além das dificuldades que os estudantes traziam por uma formação bastante deficitária no ensino básico, tive de aprender a lidar com conversas incessantes durante as aulas e com a recusa em ouvir-me ou em parar um pouco para prestar uma atenção mínima no que eu tinha a dizer. Um quadro já bastante comum na educação básica, e que também é recorrente em instituições de ensino superior privado lucrativo. O que ensinar? Como ensinar? E o mais fundamental: como se relacionar com esse público novo do ensino superior no Brasil, sem ser autoritário, mas também sem cair numa postura que permita o caos e negligencie o aprendizado efetivo dos estudantes? Essas são algumas das muitas perguntas que professores da área de Ciências Sociais temos que cada vez mais nos fazer, ainda mais num momento em que as novas tecnologias da informação e do conhecimento alteram profundamente a relação com as atividades de leitura e escrita.

\section{ESTUDANTES DAS CLASSES POPULARES NO ENSINO SUPERIOR}

A diversidade social de estudantes nessa instituição privada de ensino superior era bem grande. Apesar do predomínio dos que já trabalhavam e pertenciam às chamadas classes populares, as profissões e ocupações eram bastante variadas: havia carcereiros, policiais, agentes de segurança privada, pastores, babás, funcionários públicos, vendedores, motoristas, porteiros, etc. Porém, alguns deles, uma minoria, tinham um perfil que poderia ser considerado de uma camada social com condições socioeconômicas mais elevadas do que a dos outros. Nessa situação es- 
tava o carioca Juliano, que havia se mudado para São Paulo há pouco tempo, acompanhando a esposa, funcionária pública federal. Ele era corretor de imóveis e dizia ter uma vida bastante confortável. No entanto, essa não era a realidade predominante dos alunos com quem convivi por esses dois semestres. A maioria me relatava uma dura jornada entre trabalho e estudos. Recorrentes eram os casos daqueles que acordavam às 5 horas da manhã para trabalhar e seguir, ao fim da tarde, para a faculdade, de onde saíam somente por volta das 11 horas da noite, para retornar ao lar próximo da meia-noite, para comer algo, banhar-se, dormir e acordar novamente, poucas horas depois.

Para muitos desses estudantes, imersos em rotinas extenuantes, cursar uma faculdade de Direito representava um projeto de busca de ascensão e reconhecimento social. Gilmar, por exemplo, dizia que sempre teve vontade de ingressar no ensino superior, que a filha já estava terminando o curso dela e, assim, sentia que o seu dever com ela já estava cumprido e que, por isso, aquela seria a vez dele. Contou que a decisão de iniciar uma faculdade de Direito foi tomada quando, num sábado à tarde, deitado no sofá, assistindo à televisão, viu uma propaganda sobre aquela faculdade e seu vestibular social que anunciava: "A sua hora é agora, esta é a sua chance de fazer uma faculdade!” Segundo ele, a filha estava bastante orgulhosa de sua iniciativa de voltar a estudar depois dos 50 anos de idade. Além de casos como o de Gilmar, havia nessa instituição muitas outras situações bastante peculiares, como a de dois pais que cursavam Direito junto com as filhas. Ao observar tamanha diversidade social e etária dos estudantes, resolvi saber melhor quem eram aqueles indivíduos. Assim, a fim de obter algumas informações, deixando claro meu interesse em escrever um artigo no futuro, apliquei um questionário em duas salas de aula que estavam em semestres diferentes, no primeiro e no segundo, totalizando 93 alunos. Uma primeira observação importante diz respeito ao número um pouco maior de homens, quase $56 \%$, o que pode ser um reflexo do tipo de curso escolhido, Direito, que, supostamente, despertaria um interesse ligeiramente maior de indivíduos do sexo masculino. Alguns alunos, por exemplo, demonstraram que a motivação principal estava ligada à possibilidade de prestar concurso para uma vaga de delegado de polícia, posição hegemonicamente ocupada por homens.

A distribuição dos alunos quanto à idade, por sua vez, apareceu como um dado fundamental para entender esses estudantes e a composição contemporânea desse ensino superior privado, pois apenas $23,7 \%$ deles, no primeiro e segundo semestres da faculdade, tinham até 20 anos de idade. A grande maioria dos estudantes do primeiro ano do curso estava distribuída, quanto à idade, do seguinte modo: $35,5 \%$ na faixa etária de 21 a 30 anos; $18,3 \%$ na faixa de 31 a 40 anos; $15,0 \%$ na faixa de 41 a 50 anos e 6,4\% tinha idade superior a 50 anos, 
demonstrando que muitos deles ficaram um bom tempo afastados do sistema escolar formal.

A questão da diversidade etária em sala de aula implicava conflitos intergeracionais entre os estudantes mais novos, que se apresentavam mais inquietos, e os mais velhos, que costumavam exigir mais silêncio e disciplina para que pudessem prestar atenção no que o professor dizia. Porém, havia também experimentações de um estilo juvenil por indivíduos que já tinham ultrapassado a faixa etária considerada jovem. Uma das estudantes mais velhas, Geralda, de 53 anos, morava com dois filhos com deficiência, que criava sozinha, pois estava separada do pai deles, o qual, segundo ela, não lhe ajudava em nada. Geralda relatou-me que nunca teve apoio da família para estudar, que havia casado cedo e que, por isso, adiara o sonho de realizar uma faculdade. O pai dela, contou-me a estudante, apoiava apenas os filhos homens a prosseguir nos estudos. Logo após iniciar o curso de Direito, ela ingressou num programa estadual que concede bolsas de estudos em instituições privadas de ensino superior em troca de trabalho como educador social em escolas públicas aos fins de semana, o Escola da Família, e começou, assim, a conviver com pessoas mais novas. Numa festa, realizada na casa dela com os colegas estudantes universitários bolsistas com os quais trabalhava nos fins de semana, para a qual fui convidado, ela disse que era a primeira vez que recebia amigos e que estava muito feliz por isso, sentindo-se até mais jovem. Por um lado, esse trabalho aos fins de semana para garantir uma bolsa de estudos aumentava ainda mais a sua já extensa e extenuante jornada como mãe, trabalhadora e estudante, mas, por outro, proporcionava-lhe um sentimento de pertencimento e reconhecimento social que não havia experimentado antes.

Uma parcela considerável desses estudantes já tinha filhos, mais de $40 \%$, e, como esperado para um curso de período noturno, formado predominantemente por integrantes das classes populares, quase $90 \%$ deles trabalhavam. Dessa maneira, em alguns momentos, principalmente nas confraternizações estudantis, a carga horária pesada dedicada às obrigações familiares ou ao trabalho poderia mostrar-se mais leve, ainda que tênue e temporariamente, por meio de certa vivência de um estilo universitário cuja representação simbólica é fortemente associada a um modo de vida juvenil.

Outra dimensão importante da configuração dessas duas turmas relacionava-se ao aspecto religioso, que se mostrou relevante, aliás, no próprio andamento das aulas. O levantamento apresentou um panorama bastante diversificado das afiliações religiosas e trouxe dados que se relacionam diretamente com as mudanças mais recentes na configuração da adesão e prática religiosa no Brasil. Houve uma considerável predominância de estudantes que se declararam evangélicos $(41,94 \%)$, seguidos por católicos (28\%). Destaque para quatro pessoas, ou 4,3\% do 
total, que se declararam cristãos independentes ou evangélicos não praticantes, mas que foram agrupados como evangélicos. Um desses não praticantes definiu-se como um evangélico de princípios, mas que não frequentava nenhuma igreja.

A maioria dos estudantes era oriunda de escolas públicas (85\%) e havia entre eles uma parcela relevante (15\%) que tinha cursado o ensino médio na modalidade de Educação de Jovens e Adultos (EJA). Além disso, a experiência no ensino superior era totalmente nova para a maior parte deles $(62,4 \%)$, pois compunham a primeira geração de suas famílias a cursar uma faculdade, como muitos gostavam de dizer com orgu1ho. Havia alguns cujos pais eram analfabetos. A trajetória, no entanto, não se revelava fácil e mais de $20 \%$ deles estavam iniciando um segundo curso superior, sem terem terminado o anterior, por não conseguirem pagar ou conciliar os estudos com o trabalho.

Além disso, 77\% dos estudantes nasceram na capital paulista ou em sua Região Metropolitana. A localização geográfica da instituição de ensino superior mostrou-se como critério importante para a sua esco1ha, pois 75\% dos estudantes moravam na Zona Leste da cidade, mesma região da faculdade que cursavam. Dos que residiam em outras localidades mais distantes, o extenso deslocamento era justificado, segundo os próprios, pela proposta de vestibular social que essa instituição de ensino superior oferecia, com mensalidades mais reduzidas do que a média das outras na época. Eles estavam lá, portanto, não pela qualidade dos cursos ou pelo reconhecimento social da instituição, mas sim porque esta oferecia preços atrativos e oportunidades de bolsas e, em grande medida, por ela se situar mais próximo de suas casas.

Esse levantamento de dados indica, portanto, um maior acesso de indivíduos oriundos das classes populares ao ensino superior privado lucrativo, havendo, principalmente no período noturno, uma forte presença de estudantes trabalhadores de diferentes faixas etárias. Pode-se pensar, a partir dessa constatação e de outras reflexões sobre as classes populares na periferia de São Paulo, que haveria uma transformação dos anseios desse público, pois, como demonstra James Holston (2013), historicamente, as concepções de cidadania elaboradas pelos mais pobres se deram a partir de sua ocupação dos bairros nas periferias das grandes cidades. Noções e práticas próprias de cidadania que se produziram por meio das experiências de tornar-se proprietário, de participar de movimentos sociais por melhorias dos bairros e de ingressar no mercado consumidor. Primeiro houve a ocupação dos bairros, mesmo sem nenhuma estrutura mínima. Depois, vieram as reivindicações pela legalização dos terrenos ocupados e, enfim, as lutas pela chegada da energia elétrica, saneamento básico e asfalto. Concomitante a esse processo de ocupação dos bairros e construção de um espaço da cidade para os mais pobres, houve as reivindicações por educação, principal- 
mente pela construção de escolas e creches, como demonstra Marília Sposito (1984). A autora apresenta a expansão da rede pública de educação básica como o resultado de uma ação bastante contraditória do Estado a partir de muitas relações de força que colocaram diferentes grupos sociais em oposição. Ainda que não se possa estabelecer uma relação causal nem unívoca entre o processo histórico de formação das periferias urbanas, com suas lutas e conquistas sociais específicas, e o crescimento do número de indivíduos a acessar o ensino superior, há de se levar em conta as transformações sociais que o considerável aumento dessa perspectiva, que se apresentava antes com uma possibilidade extremamente reduzida, ocasiona no cotidiano e nos projetos de vida das camadas populares. O próprio surgimento dos movimentos sociais de pressão por melhorias no acesso ao ensino superior, com os cursinhos pré-vestibulares populares e as propostas de gratuidade em taxas de inscrição e/ou do fim do vestibular, além das políticas de ação afirmativa, como demonstrado por Sabrina Moehlecke (2004), de certa maneira, apontam para uma nova pauta importante de luta social para estudantes das classes populares nas periferias urbanas. Portanto, podem ser percebidas similaridades entre o modo como ocorreu esse crescimento do acesso ao ensino superior lucrativo e precarizado e como se deu o processo histórico de formação das periferias urbanas, considerado o alinhamento à dinâmica das lutas sociais e de conquista de certa cidadania precária, incompleta ou flexível, conforme a definição de Aihwa Ong (1999). A noção proposta por essa autora, a de cidadania flexível, pode ser compreendida como as táticas que respondem de modo fluido e oportunista às condições de mobilidade social que os mercados periféricos oferecem. Trata-se, portanto, de um tipo de cidadania regido pelas lógicas do mercado.

Os estudantes com os quais trabalhei nessa instituição e sua realidade social podem ser situados no âmbito de um contexto de ascensão de certa classe social tão aclamado pelo discurso midiático e publicitário, principalmente a partir do segundo mandato presidencial de Lula, com a chamada nova classe média ou nova classe C. Muitos autores têm, entretanto, contestado esse discurso e ressaltam que, em vez de uma nova classe média, o que se teve foi a ascensão de um certo estrato da classe trabalhadora ou uma nova classe trabalhadora. Segundo Márcio Pochmann (2012), o discurso que teoriza sobre a chamada nova classe média, surgida nos anos 2000, pós-governo Lula, refletiria, na realidade, o crescimento de um segmento social mais baixo da classe trabalhadora, cuja renda per capita não ultrapassaria um salário mínimo. Tratase, conforme esse autor, dos estratos mais baixos da pirâmide social. Pochmann (2012) afirma ainda que esse segmento social apresentaria desafios para as instituições sociais e políticas tradicionais. Jessé Souza (2010), por sua vez, afirma que essa chamada nova classe média seria, 
na verdade, uma nova classe trabalhadora, que ele denominou "batalhadores brasileiros”. Essa classe teria ascendido, segundo Souza (2010), a partir de um enorme esforço pessoal e pela conciliação de vários turnos de trabalho aos quais, algumas vezes, se junta também o turno escolar. Trata-se de uma classe social cujo principal capital herdado da família seria a disposição para o trabalho duro.

A discussão sobre essa nova configuração da classe trabalhadora no Brasil se coaduna com alguns estudos mais recentes sobre um maior acesso dos estudantes trabalhadores a instituições privadas de ensino superior. Maria Corrochano (2013) demonstra que, há algum tempo, o perfil clássico de universitário de classe média e/ou de elite que se mobiliza politicamente em torno do movimento estudantil tem se modificado substancialmente. A partir da relação com o mundo do trabalho e com a família, Geraldo Romanelli (2010) ressalta a existência de três categorias de estudantes universitários no Brasil: o estudante de tempo integral, que seria aquele totalmente mantido pela família e ainda fora do mercado de trabalho; o estudante-trabalhador, em referência àquele que trabalha, mas ainda continua dependendo parcialmente dos recursos familiares; e o trabalhador-estudante, aquele que também já está inserido no mercado de trabalho, mas sem contar com qualquer ajuda financeira da família em sua trajetória universitária. Particularmente no ensino superior privado, um novo perfil de estudante começa a predominar e esse já não pode ser definido nem como de classe média e, em muitos casos, nem como jovem, como apontam Comin e Barbosa (2011). Esses autores destacam a presença muito maior do adulto trabalhador no ensino superior, caracterizando esse público não como estudante trabalhador, mas sim como trabalhador estudante, conforme a discussão de Romanelli (2010). Desse modo, a partir da expansão do ensino superior privado, inverte-se a noção de que a inserção nele garantiria o acesso ao mercado de trabalho formal mais qualificado, pois, como demonstram Comin e Barbosa (2011), em muitos casos é a presença prévia no mercado de trabalho que garante o acesso a essa modalidade de educação. 
Pochmann (2012) afirma que esse contexto de ascensão de segmentos sociais da base da pirâmide social teria propiciado um considerável aumento da geração de postos de trabalho para pessoas na faixa etária entre 45 e 64 anos. As questões que eu enfrentava em sala de aula revelavam-se, portanto, claramente como o resultado da combinação de um novo arranjo social com novas políticas de financiamento do ensino superior, que permitiu a chegada de indivíduos de um estrato social específico, cujo acesso ao ensino superior era bastante restrito anteriormente, a novas instituições privadas de ensino.

Entendo aqui a noção de classes populares a partir da reflexão de Thompson (1987, p. 12) sobre classes sociais, não como uma estrutura e nem como uma posição social que pode ser definida previamente, mas sim como algo que se produz a partir de um conjunto de experiências: "A classe é definida pelos homens enquanto vivem sua própria história e, ao final, esta é sua única definição”. Bernard Charlot (2000) discute as ideias de famílias consideradas populares ou desfavorecidas, definindo-as como aquelas a ocupar uma posição social dominada, vivendo em situação de pobreza ou precariedade. No Brasil, o uso da noção de classes ou camadas populares, como apontam Eder Sader e Maria Célia Paoli (1986), indica a heterogeneidade de sua constituição. Conforme os autores, apesar de não haver nela certa precisão na definição de fronteiras de classe, a noção de classes populares urbanas aponta, inclusive, uma alteração no enfoque analítico das fronteiras entre classes para "a compreensão específica da prática dos atores sociais em movimento", principalmente a partir de uma série de transformações que se deram nos anos 1970 e 1980, com as mobilizações políticas e sociais nas periferias urbanas, em torno de certas reivindicações políticas por melhorias nas condições locais de vida (SADER; PAOLI, 1986, p. 59). Almeida (2009), por sua vez, em discussão sobre o contexto contemporâneo do acesso ao ensino superior no país, mobiliza a categoria "estudantes com desvantagens socioeconômicas e educacionais". Nesse caso específico, ele trabalha com a questão do acesso de estudantes desse estrato social a uma universidade pública de prestígio, a Universidade de São Paulo (USP), reconhecendo ainda certas singularidades e a dimensão relacional da posição social, pois, conforme o autor, se eles, por um lado, estariam numa condição de dominados, tendo em vista que mal posicionados socialmente em relação aos estudantes de camadas sociais superiores nos cursos mais concorridos, por outro, também estariam mais bem posicionados em relação às suas frações de classe de origem (ALMEIDA, 2009). Com isso, o autor denomina esses estudantes como "pobres diferenciados". No caso dos estudantes com quem interagi durante essa 
minha experiência docente, a dimensão da classe social despontava de muitas formas, como pela própria configuração da relação com o saber, definida por Bernard Charlot (1996, p. 49) como "uma relação de sentido, e portanto de valor, entre um indivíduo (ou um grupo) e os processos ou produtos do saber". Ao discutir a relação com o saber entre estudantes secundaristas pobres de escola de periferia na França, Charlot afirma que o vínculo que os estudantes estabelecem entre escola e profissão ou entre estudos e trabalho exprime a condição de vida desses indivíduos, pois remete à necessidade e à dificuldade de conseguir um bom trabalho que permita, por sua vez, conquistar:

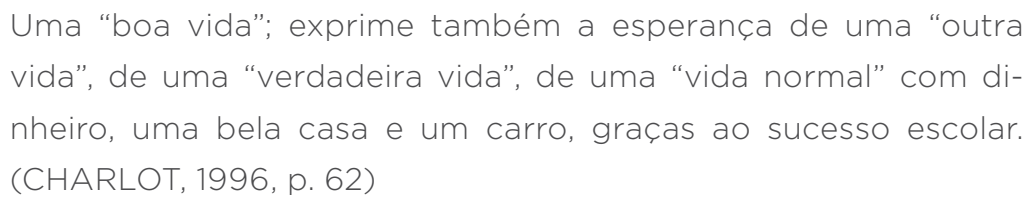

Contudo, a classe social entre os estudantes aqui abordados, além das particularidades da relação com o saber e o ensino superior, exprimia-se e formava-se por vários outros fatores, como o local de moradia, afinal a maioria deles residia num bairro pobre periférico, a relação com o trabalho, já apontada anteriormente, a idade e mesmo pela dimensão religiosa. Um número considerável afirmou-se evangélico. Havia, inclusive, os que se identificavam como evangélicos não praticantes. Um dos estudantes que diziam compartilhar dos valores cristãos evangélicos, mas que não pertenciam a nenhuma denominação religiosa, declarava-se também ex-presidiário. Jessé Souza (2010) associa as religiões pentecostais ou neopentecostais às classes dominadas e às classes batalhadoras brasileiras. O autor destaca a capacidade dessas formas religiosas em adaptar-se aos anseios das classes populares moradoras das periferias urbanas no Brasil, o que explicaria seu sucesso. Por outro lado, Carlos Gutierrez (2017), em tese sobre o mundo evangélico como espaço de elaboração de projetos de vida para as camadas populares, demonstra como o campo evangélico tem trazido novas questões que reconfiguram a dimensão de certos anseios de classe social, na medida em que passa a apresentar aos seus fiéis uma perspectiva do empreendedorismo como ascensão social e libertação da pobreza, em contraposição ao trabalho assalariado, considerado desvalorizado e relacionado a uma certa ideia de pequenez social.

A nova composição social no ensino superior ampliou também uma diversificação etária, pois proporcionou a indivíduos em idades mais avançadas uma possibilidade de retomar a oportunidade que não tiveram anteriormente, quando mais jovens. Para se entender as peculiaridades dessa turma de estudantes é preciso não só refletir sobre a chegada desse público pertencente a uma classe social que historica- 
mente foi alijada do ensino superior no Brasil, mas também discutir sobre como muitos desses indivíduos têm tentado nos últimos anos, por meio de algumas estreitas janelas de oportunidades que se abriram, conquistar esse direito, mesmo que numa idade mais avançada, fora da faixa etária mais comumente esperada para essa modalidade de ensino. Ruth Cardoso e Helena Sampaio (1994) afirmam que, já no final dos anos 1960, ocorrera uma primeira mudança no público do ensino superior privado no Brasil, com a expansão ocorrida no período, reduzindo assim a sua homogeneidade. Conforme Almeida (2014b), nesse momento, ainda que se constatasse grande predomínio dos estudantes das camadas médias, já houve um primeiro movimento de diversificação, com uma maior entrada de estudantes com idade mais elevada e de trabalhadores. Contudo, segundo esse mesmo autor, é nos anos 1990, com o início dessa mais recente onda de expansão do ensino superior e também com um considerável aumento no número de vagas no ensino médio, que o quadro atual começa se configurar, com um maior acesso de indivíduos das classes média baixa e de baixa renda. Dessa maneira, o que se apresentou para mim em sala de aula revelava um pouco da complexidade dos processos mais recentes de construção de novas formas de experimentar o ensino superior no Brasil, configuradas em associação com a própria experiência diversificada de vida desses estudantes.

\section{CONSIDERAÇÕES FINAIS}

Ensaiei aqui uma descrição analítica dessa minha experiência docente numa instituição de ensino superior privado lucrativo. Ao longo dos últimos anos em que tenho trabalhado em instituição pública federal de ensino superior, primeiro, lecionando tópicos de Ciências Sociais para estudantes de cursos da área da saúde e, atualmente, trabalhando com a questão da educação dentro do próprio curso de Ciências Sociais, a ideia de produzir tal texto mostrou-se ainda mais relevante. Os acontecimentos políticos que ocasionaram e foram consequência do impeachment da presidente Dilma Roussef levaram-me a retomar a necessidade de escrevê-lo, pois num momento em que as Ciências Sociais, principalmente a Antropologia e a Sociologia, têm sido questionadas em diferentes instâncias, por movimentos que acusam os docentes dessa área de pregação ideológica, discutir o seu ensino para não cientistas sociais mostra-se fundamental. Por outro lado, da mesma forma que a ambiguidade da conciliação de classes lulista revelou uma série de paradoxos e inconsistências, apesar de uma considerável inclusão social, conforme expõe André Singer (2012), a chegada ao ensino superior dos alunos aqui apresentados também é uma das reveladoras consequências dessas políticas públicas contraditórias, que, 
se abriram uma maior possibilidade de acesso ao ensino superior, também produziram o financiamento e a oferta de uma formação educacional bastante deficiente e incompleta.

Políticas públicas como o Fundo de Financiamento Estudantil (Fies) ${ }^{3}$ e o Programa Universidade para Todos (Prouni) $)^{4}$, talvez as principais ações para inclusão no ensino superior dos governos petistas de Lula e Dilma, permitiram o surgimento desse quadro, dando continuidade e aperfeiçoando o modelo de estímulo a instituições privadas de ensino superior já desenvolvido intensamente durante o governo de Fernando Henrique Cardoso (FHC). Porém, foi no governo Lula, em 2007, que suas regras foram alteradas, permitindo financiar desde então não mais apenas 70\%, mas sim 100\% das mensalidades (ALMEIDA, 2014a). A faculdade em que estive desenvolveu um modo bastante particular de se aproveitar desse último dispositivo. Ela oferecia uma mensalidade bastante baixa, anunciada como bolsa de estudos, e, posteriormente, incentivava os alunos a buscarem um financiamento do Fies ou a se cadastrarem num outro programa do governo do Estado de São Paulo de concessão de bolsas de estudos em universidades privadas em troca de trabalho voluntário nos fins de semana em escolas públicas de educação básica, o Escola da Família. A pesquisa de Almeida (2014a) sobre o Prouni aponta para a ambiguidade dos avanços sociais durante as gestões petistas, que trazem certa inclusão social, ainda que incompleta, para camadas mais desfavorecidas da população brasileira, ao mesmo tempo que, por essas mesmas políticas públicas voltadas aos mais pobres, financiam setores empresariais responsáveis por instituições privadas e lucrativas de ensino superior. Essa minha experiência localizada revelou-me muito sobre as contradições da educação, da inclusão social e das políticas públicas, nos últimos 25 anos, em nosso país, principalmente no setor privado lucrativo de ensino superior.

Nesse sentido, o problema do aluno que não consegue ler Marx no carro-forte, enquanto faz transporte de valores, tem também se transformado no problema dos professores que encontram dificuldades não apenas em ensinar Marx, mas em discutir qualquer outro autor ou tema que remeta a um saber com um fim em si mesmo e com pouca finalidade prática ou de ganho comercial. Essa tarefa torna-se ainda mais complicada num contexto em que os estudantes e a própria instituição privada de ensino superior estão em busca apenas de um retorno imediato e lucrativo. $\mathrm{O}$ acesso ao ensino superior para esses estudantes envolve, fundamentalmente, um desejo de reconhecimento social que se dá pelo consumo de uma determinada mercadoria: um diploma de ensino superior. Este, acredita a maioria deles, garantiria melhores empregos, status social e estabilidade. Muitos dos alunos com quem conversei diziam que o curso de Direito havia sido escolhido porque, na verdade, queriam tornar-se juízes ou delegados. Não por acaso, a relação 
com os professores entrava na chave do direito do consumidor, com os estudantes indo à coordenação reclamar de posturas ou práticas pedagógicas de determinados docentes ou ameaçando fazê-lo, como ocorreu comigo. Fundamental problematizar o pouco apreço pela figura do professor, considerado um profissional fracassado. Eu ali frustrei muitos dos estudantes que, inclusive no início me chamavam de doutor, por não ser bacharel em Direito. Por isso, até mesmo uma das estudantes com as maiores dificuldades de leitura e escrita da turma mostrou-se bastante decepcionada com a notícia, tratando-me com certo desdém a partir daí. Valorizavam, no entanto, conforme contaram-me alguns estudantes, outro jovem professor, advogado, que, espertamente, apresentava-se em sala como um profissional bem-sucedido, que trabalhava em escritório de advocacia e dizia faturar mais de cem mil reais por mês. Porém, pouco há o que se cobrar dos estudantes a respeito disso, quando estão numa instituição que pagou mais de um milhão de reais por um sistema on-line de inserção de notas, mas pagava pouco mais de 20 reais pela hora-aula de seus professores.

Cabe destacar que, apesar de a maioria dos alunos ter apresentado grandes dificuldades de leitura e escrita em minhas aulas, seja pela falta de tempo para ler os textos previamente, seja por uma formação deficitária na educação básica, havia também aqueles com ótima formação e capacidade de reflexão, como um jovem, morador de Cidade Tiradentes - bairro pobre da periferia, no extremo leste da cidade - o Alfredo, que gostava de ler e ostentava sobre a mesa o livro Vigiar e punir, de Michel Foucault, logo após eu comentar com ele sobre esse autor numa das aulas. Nesse ponto, apesar de até aqui apresentar um cenário bastante negativo, é importante ressaltar que havia sim estudantes para quem aquela era a única e grande chance de suas vidas e que apreendiam o conhecimento como um fim em si mesmo. Esses evidentemente que queriam um trabalho e uma posição social melhores, mas buscavam também algo mais importante que não fosse apenas um retorno lucrativo imediato. Dessa maneira, como demonstra Almeida (2014a), é preciso entender que as políticas públicas que ampliaram o acesso ao ensino superior privado lucrativo trouxeram, do mesmo modo, esse outro lado, o de uma certa inclusão social para uma camada da população que é composta pela primeira geração de sua família a vislumbrar tal possibilidade. Compreender quais são os muitos significados dessa experiência para as pessoas envolvidas mostra-se também fundamental. Ao mesmo tempo, não se deve fugir ao questionamento do tipo de ensino e formação que está sendo oferecido, nem se furtar de refletir sobre qual cidadania se alcança com um ensino superior tão precarizado para estudantes e docentes. Coulon (2008), em discussão sobre a expansão do ensino superior na França, aponta para o sucesso quantitativo da democratização do acesso à universidade nesse país, mas ressalta as di- 
ficuldades desse processo e uma alta taxa de fracasso. Ou seja, democratizou-se apenas o acesso às instituições de ensino superior, mas não o acesso ao saber. Conforme o autor, vários fatores levariam a esse fracasso, como o crescimento de uma cultura individualizante na formação universitária que despreza o ensino e uma "nova relação dos estudantes com saber marcada, frequentemente, por uma ausência de referência a textos básicos do pensamento" e "por uma cultura da imediaticidade" (COULON, 2008, p. 21).

Essa é uma questão fundamental para professores com formação em Ciências Sociais. Com o aumento numérico dos cursos de pós-graduação dessa área e a pouca perspectiva de nova expansão da rede pública federal de ensino superior, o campo de trabalho tende cada vez mais a ser esse, o de discutir seus temas com estudantes de outros cursos - muitas vezes pouco motivados a estudar tais questões -, produzindo um diálogo interdisciplinar que pode ser muito proveitoso, principalmente se conseguir despertar o interesse por uma relação não utilitária com o conhecimento e com a própria vida. Talvez seja o caso de começar a pensar em outras possibilidades de atuação e de formação para os cientistas sociais que não sejam tão endogâmicas, voltadas somente para formar professores doutores com a finalidade principal de trabalhar em faculdades públicas de Ciências Sociais. Uma parte desse campo de trabalho continuará, claro, nos cursos de Ciências Sociais e nas universidades públicas, mas também serão os outros cursos e as instituições privadas um espaço importante e considerável. Como mostram Sampaio e Sanchez (2017), apesar de certa expansão do setor público, em São Paulo, o setor privado está muito acima no que se refere ao número de instituições e matrículas em cursos de graduação. Precisamos, portanto, discorrer a respeito disso, sobre como é ler Marx numa universidade privada cujo lucro é o objetivo primordial, até mesmo para questionar a viabilidade desse tipo de instituição, inclusive para pensar nosso futuro como intelectuais, pesquisadores e professores. Vamos continuar falando apenas para nós mesmos? O que certamente é mais seguro. Ou vamos nos arriscar e encarar o desafio de debater a tarefa de fazer com que estudantes, que não são das Ciências Sociais e também não compõem o público classe média de outrora, desenvolvam um pouco de admiração por essa forma de pensar e entender o mundo, incentivando-os a ler Marx, ou Tocqueville, ou Lévi-Strauss, ou o que quer que queiramos que eles leiam, nos carros-fortes, bancos, supermercados, restaurantes, lojas, fábricas, escritórios, agências de viagens, ou qualquer outro lugar de trabalho? Considero, nesses tempos de incerteza, que essas são questões fundamentais para pensarmos nosso campo de trabalho, nossa atuação política, o futuro do ensino superior e a formação do cientista social no Brasil. 


\section{REFERÊNCIAS}

ALMEIDA, Wilson. USP para todos? Estudantes com desvantagens socioeconômicas e educacionais e fruição da universidade pública. São Paulo: Musa, 2009.

ALMEIDA, Wilson. Prouni e o ensino superior privado lucrativo em São Paulo: uma análise sociológica. São Paulo, Musa/Fapesp, 2014a.

ALMEIDA, Wilson. Estudantes com desvantagens sociais e os desafios da permanência na universidade pública. In: PIOTTO, D. (Org.). Camadas populares e universidades públicas: trajetórias e experiências escolares. São Carlos: Pedro \& João, 2014b. p. 239-272.

BARREIRA, Irlys. O ofício de ensinar para iniciantes: contribuições ao modo sociológico de pensar. Revista de Ciências Sociais, Fortaleza, v. 45, n. 1, p. 63-85, jan. 2014

BECKER, Howard; GEER, Blanchee; HUGHES, Everett; STRAUSS, Anselm. Boys in white: student culture in medical school. New Brunswick and London: Transaction Publishers, 1977.

CARDOSO, Ruth; SAMPAIO, Helena. Estudantes universitários e trabalho. Revista Brasileira de Ciências Sociais, São Paulo, v. 9, n. 26, p. 30-50, out. 1994.

CHARLOT, Bernard. Relação com o saber e com a escola entre estudantes da periferia. Cadernos de Pesquisa, São Paulo, n. 97, p. 47-63, maio 1996.

CHARLOT, Bernard. Da relação com o saber: elementos para uma teoria. Porto Alegre: Artes Médicas Sul, 2000.

COMIN, Alvaro; BARBOSA, Rogério. Trabalhar para estudar: sobre a pertinência da noção de transição escola-trabalho no Brasil. Novos Estudos - CEBRAP, São Paulo, n. 91, p. 75-95, nov. 2011.

CONNELL, Raewyn. Bons professores em um terreno perigoso: rumo a uma nova visão da qualidade e do profissionalismo. Educação e Pesquisa, São Paulo, v. 36, n. especial, p. 166-184, 2010 .

CORROCHANO, Maria. Jovens trabalhadores: expectativas de acesso ao ensino superior. Avaliação: Revista da Avaliação da Educação Superior, Campinas; Sorocaba, SP, v. 18, n. 1, p. 23-44, mar. 2013.

COULON, Alain. A condição de estudante: a entrada na vida universitária. Salvador: EDUFBA, 2008.

GEERTZ, Clifford. A interpretação das culturas. Rio de Janeiro: LTC, 1989.

GUSDORF, Georges. Professores para quê: para uma pedagogia da pedagogia. São Paulo: Martins Fontes, 2003.

GUTIERREZ, Carlos. A reflexividade evangélica a partir da produção crítica e construção de projetos de vida na Igreja Universal do Reino de Deus. 2017. Tese (Doutorado) - Universidade Estadual de Campinas, Campinas, 2017.

HOBBES, Thomas. Leviatã. São Paulo: Martins Fontes, 2003.

HOLSTON, James. Cidadania insurgente: disjunções da democracia e da modernidade no Brasil. São Paulo: Cia. das Letras, 2013.

LAHIRE, Bernard. Viver e interpretar o mundo social: para que serve o ensino da Sociologia? Revista de Ciências Sociais, Fortaleza, v. 45, n. 1, p. 45-61, jan. 2014.

MEHAN, Hugh. Learning lessons: social organization in the classroom. Cambridge Mass: Harvard University Press, 1979.

MOEHLECKE, Sabrina. Fronteiras da igualdade no ensino superior: excelência \& justiça racial. 2004. Tese (Doutorado) - Universidade de São Paulo, São Paulo, 2004.

MILLS, Charles W. Sobre o artesanato intelectual e outros ensaios. Rio de Janeiro: Jorge Zahar, 2009. 
ONG, Aihwa. Flexible citizenship: the cultural logics of transnacionality. Durham, NC: Duke University Press, 1999.

POCHMANN, Marcio. Nova classe média: o trabalho na base da pirâmide social brasileira. São Paulo: Boitempo, 2012.

ROMANELLI, Geraldo. Famílias de camadas médias e escolarização superior dos filhos: o estudante-trabalhador. In: NOGUEIRA, Maria Alice; ROMANELLI, Geraldo; ZAGO,

Nadir (Org.). Família e escola: trajetórias de escolarização em camadas médias e populares. Petrópolis, RJ: Vozes, 2010. p. 99-124.

SADER, Eder; PAOLI, Maria Célia. Sobre “classes populares” no pensamento sociológico brasileiro. In: CARDOSO, Ruth (Org.). A aventura antropológica: teoria e pesquisa. Rio de Janeiro: Paz e Terra, 1986. p. 39-67.

SAMPAIO, Helena; SANCHEZ, Ilara. Formação acadêmica e atuação profissional de docentes em educação: USP e Unicamp. Cadernos de Pesquisa, São Paulo, v. 47, n. 166, p. 1268-1291, out./dez. 2017.

SINGER, André. Os sentidos do lulismo: reforma gradual e pacto conservador. São Paulo: Cia. das Letras, 2012.

SOUZA, Jessé. Os batalhadores brasileiros: nova classe média ou nova classe trabalhadora? Belo Horizonte: Editora UFMG, 2010.

SPOSITO, Marília. O povo vai à escola: a luta popular pela expansão do ensino público em São Paulo. São Paulo: Loyola, 1984.

TARDIF, Maurice; LESSARD, Claude. 0 trabalho docente: elementos para uma teoria da docência como profissão de interações humanas. Petrópolis, RJ: Vozes, 2014.

THOMPSON, Edward. A formação da classe operária inglesa. Rio de Janeiro: Paz e Terra, 1987. 